OPEN ACCESS

Edited by:

Francesca Sparvoli,

National Research Council, Italy

Reviewed by:

Ashwani Pareek,

Jawaharlal Nehru University, India

Rosa Rao,

University of Naples Federico II, Italy

*Correspondence:

Bingliang $X u$

xubl@gsau.edu.cn

Specialty section:

This article was submitted to Crop Science and Horticulture,

a section of the journal

Frontiers in Plant Science

Received: 03 July 2016 Accepted: 02 September 2016 Published: 15 September 2016

Citation:

Zhang S, Gan Y and Xu B (2016) Application of Plant-GrowthPromoting Fungi Trichoderma Iongibrachiatum T6 Enhances

Tolerance of Wheat to Salt Stress through Improvement of Antioxidative Defense System and Gene Expression. Front. Plant Sci. 7:1405 doi: 10.3389/fpls.2016.01405

\section{Application of Plant-Growth- Promoting Fungi Trichoderma longibrachiatum T6 Enhances Tolerance of Wheat to Salt Stress through Improvement of Antioxidative Defense System and Gene Expression}

\author{
Shuwu Zhang ${ }^{1,2,3}$, Yantai Gan ${ }^{4}$ and Bingliang $X u^{1,2,3 *}$ \\ ${ }^{1}$ College of Grassland Science, Gansu Agricultural University, Lanzhou, China, ${ }^{2}$ Key Laboratory of Grassland Ecosystems, \\ The Ministry of Education of China, Lanzhou, China, ${ }^{3}$ Sino-U.S. Centers for Grazingland Ecosystems Sustainability, Lanzhou, \\ China, ${ }^{4}$ Gansu Provincial Key Laboratory of Aridland Crop Sciences, Gansu Agricultural University, Lanzhou, China
}

Soil salinity is a serious problem worldwide that reduces agricultural productivity. Trichoderma longibrachiatum T6 (T6) has been shown to promote wheat growth and induce plant resistance to parasitic nematodes, but whether the plant-growth-promoting fungi T6 can enhance plant tolerance to salt stress is unknown. Here, we determined the effect of plant-growth-promoting fungi T6 on wheat seedlings' growth and development under salt stress, and investigated the role of $\mathrm{T} 6$ in inducing the resistance to $\mathrm{NaCl}$ stress at physiological, biochemical, and molecular levels. Wheat seedlings were inoculated with the strain of T6 and then compared with non-inoculated controls. Shoot height, root length, and shoot and root weights were measured on 15 days old wheat seedlings grown either under $150 \mathrm{mM} \mathrm{NaCl}$ or in a controlled setting without any $\mathrm{NaCl}$. A number of colonies were re-isolated from the roots of wheat seedlings under salt stress. The relative water content in the leaves and roots, chlorophyll content, and root activity were significantly increased, and the accumulation of proline content in leaves was markedly accelerated with the plant growth parameters, but the content of leaf malondialdehyde under saline condition was significantly decreased. The antioxidant enzymes-superoxide dismutase (SOD), peroxidase (POD), and catalase (CAT) in wheat seedlings were increased by 29, 39, and 19\%, respectively, with the application of the strain of T6 under salt stress; the relative expression of SOD, POD, and CAT genes in these wheat seedlings were significantly up-regulated. Our results indicated that the strain of T6 ameliorated the adverse effects significantly, protecting the seedlings from salt stress during their growth period. The possible mechanisms by which T6 suppresses the negative effect of $\mathrm{NaCl}$ stress on wheat seedling growth may be due to the improvement of the antioxidative defense system and gene expression in the stressed wheat plants.

Keywords: Trichoderma longibrachiatum T6, wheat seedling, salt stress, plant-growth-promoting, antioxidative defense system and gene expression 


\section{INTRODUCTION}

Salt stress is one of the major abiotic stresses that affects plant growth, development, and crop yield (Ma et al., 2012; Rivero et al., 2014). Wheat (Triticum aestivum), the most important cereal crop in the world, is considered to be salt sensitive (Tian et al., 2015). Grown under salt conditions, wheat plants often produce a significantly low grain yield with poor quality. Studies have shown that salt stress can induce several morphological, physiological, and metabolic responses of plants, which causes ROS stress and osmotic stress in plants, leading to increased peroxidation of lipid and antioxidant enzyme inactivation (Garg and Manchanda, 2009). Also, plants grown under salt stress conditions usually synthesize several kinds of soluble compounds including soluble sugars and proteins, which may help adjust osmoticum, retain cell turgor, and stabilize cell structures (Bartels and Sunkar, 2005).

At the present time, about $6 \%$ of the arable land on the earth is salt affected, especially in arid and semiarid regions (Bui, 2013). This seriously threatens global agricultural sustainability and food security. Thus, it is critically important to develop effective and practical techniques to alleviate the negative effects of salt stress on plant growth and development. Conventional breeding and transgenic technology have been used to develop new cultivars with improved salt tolerant traits, but breeding salt tolerance has not been successful (Phang et al., 2008). The long breeding cycle and low breeding efficiency for the quantitative trait presents challenges. Transgenic technology has the ability to incorporate salt tolerant genes in new plant materials (Sairam and Tyagi, 2004; Sahi et al., 2006; Lu et al., 2007), but the effectiveness has been low and also enveloped in controversy (Zou et al., 2015). Furthermore, gene loss, high cost, and other regulatory issues are the main bottlenecks for commercial transgenic plants use (Glick, 2007). A newer attempt is to apply exogenous compounds to decrease the negative effect of abiotic stress; this technique has been shown to increase plant tolerance to salt stress, such as using oligochitosan (Ma et al., 2012), nitric oxide and calcium nitrate (Tian et al., 2015), chitooligosaccharides (Zou et al., 2015), and jasmonic acid (Qiu et al., 2014) in wheat, as well as gibberllic acid and calcium chloride in linseed (Linum usitatissimum; Khan et al., 2010), and ascorbic acid in broad bean (Vicia faba; Younis et al., 2010). These exogenous compounds have been shown to improve the salt tolerance of plants, but the exact physiological mechanisms are unknown. A new, innovative technique that has attracted a great deal of attention in recent years, is to use plant-growth-promoting bacteria and fungi to induce plant resistance to abiotic stress. It is an effective approach for enhancing plant tolerance to salt stress and this approach may play a role in the development of sustainable agricultural systems. Trichoderma spp. is one of

\footnotetext{
Abbreviations: AN, acid ninhydrin; ASA, aqueous sulfosalicylic acid; BSA, bovine serum albumin; CAT, catalase; CFUs, colony-forming units; GAA, glacial acetic acid; $\mathrm{H}_{2} \mathrm{O}_{2}$, hydrogen peroxide; MDA, malondialdehyde; PBS, phosphate buffer solution; POD, peroxidase; ROS, reactive oxygen species; SOD, superoxide dismutase; TBA, thiobarbituric acid; TCA, trichloroacetic acid; TTC, triphenyl tetrazolium chloride; T6, Trichoderma longibrachiatum T6.
}

the important groups of rhizosphere microorganisms, which can impart some beneficial effects on promoting plant growth and development (Harman et al., 2004; Qi and Zhao, 2013). The Trichoderma species have also been known to be used by plants as biological control agents for controlling different species of plant fungus diseases for decades (Harman et al., 2004). Mastouri et al. (2010) have reported that Trichoderma afroharzianum T22 can enhance tomato (Solanum lycopersicum) seed germination under biotic and abiotic stresses, alleviating oxidative damage in osmotic stressed seedlings. However, the underlying mechanisms responsible for the alleviation of oxidative damage remain to be explored. Little information is available regarding the potential and possible mechanisms of plant-growth-promoting fungi T6 in enhancing the tolerance of wheat to salt stress.

Our previous studies show that Trichoderma longibrachiatum has a higher potential of parasitic and lethal effects against Heterodera avenae (Zhang et al., 2014b), but its effects on wheat are fairly high in promoting plant growth and nematode control (Zhang et al., 2014a). However, the previous studies failed to determine the possible mechanism of T6 enhancing the tolerance of wheat to salt stress. Therefore, the objectives of the present study were to (i) evaluate the effect of the strain of T6 on wheat growth under various levels of salt stress, and (ii) explore the possible mechanism of T6 in response to salt stress at physiological, biochemical, and molecular levels.

\section{MATERIALS AND METHODS}

Experiments were carried out at the Pratacultural Engineering Laboratory of Gansu Province. The replicated experiment was firstly conducted in 2014, and in order to obtain solid results, the same and entire experiment was repeated for a second run in 2015 .

\section{Fungal Inoculum Preparation}

The salt tolerance strain of T6 was obtained from the Laboratory of Plant Pathology, Gansu Agricultural University. The conidia suspension of T6 was prepared according to the method of Zhang et al. (2014b). Final suspension of $1.0 \times 10^{8}$ conidia per $\mathrm{ml}$ were prepared and stored at $4^{\circ} \mathrm{C}$.

\section{Plant Material and Treatment Conditions}

All the experiments were conducted with wheat (cv. Yongliang 4). Consistent sizes of wheat seeds were surface-sterilized with a $1 \% \mathrm{NaOCl}$ solution for $10 \mathrm{~min}$, and then thoroughly washed with distilled water six times over. Wheat seeds were soaked in T6 or sterilized distilled water overnight for $12 \mathrm{~h}$, and then transferred to Petri dishes with two layers of moist gauze for germination at $25^{\circ} \mathrm{C}$ for $24 \mathrm{~h}$ in the dark. Fifty germinated wheat seeds were planted in each transparent box (12 by 12 by $5 \mathrm{~cm}$ ) which was filled with water agar containing 0 and $150 \mathrm{mM} \mathrm{NaCl}$ (control and $\mathrm{NaCl}$, respectively) and were grown in an incubator at a day/night cycle of 16/8 h. The germinated seeds grown in transparent boxes were cultured in an incubator with a relative humidity $(\mathrm{RH})$ of $65 \%$ and a light intensity of $600 \mathrm{~mol} \mathrm{~m}^{-2} \mathrm{~s}^{-1}$. Thus, the experiments were designed for four groups, which included a 
control (neither treated with T6 nor $150 \mathrm{mM} \mathrm{NaCl}$ solution), a negative control with $150 \mathrm{mM} \mathrm{NaCl}$ stress, a positive control with T6 treatment, and a stressed group T6- $\mathrm{NaCl}$ (treated with $\mathrm{T} 6$ and $150 \mathrm{mM} \mathrm{NaCl}$ ). Each treatment was repeated six times.

\section{Number of Colonies in Wheat Root}

Fifteen days after being treated with $150 \mathrm{mM} \mathrm{NaCl}$ and the suspension of T6, number of colonies in wheat root was assessed and recorded. The ability of T6 to colonize and grow in association with wheat roots were assessed by determining final T6 densities. Root colonization was assessed following an established protocol (Zhang et al., 2015), where $1 \mathrm{~g}$ of surfacesterilized sub-samples of air-dried chopped roots was crushed in $9 \mathrm{ml}$ of sterile water with antibiotics $\left(50 \mathrm{mg}^{-1}\right.$ of streptomycin sulfate) with a sterilized pestle and mortar. The root suspension $\left(10^{-3}\right)$ was plated onto each of six 9-cm diameter Petri dishes [containing Trichoderma medium E (TME); Papavizas and Lumsden, 1982] and incubated in the growth incubator at $25^{\circ} \mathrm{C}$ for $72 \mathrm{~h}$. The number of T6 density per $\mathrm{g}$ of air-dried roots was counted from clear CFU forming on medium after dilution plating of the root suspension. Each treatment was repeated six times.

\section{Growth Parameters}

Wheat seedlings were harvested 15 days after $\mathrm{NaCl}$ treatment. Shoots and roots of wheat seedlings were separated and washed with distilled water three times, and then dried and weighed. Root length and weight were determined immediately after being grown for 15 days. For the determination of dry weight, all the samples of wheat seedling shoots and roots were oven-dried at $105^{\circ} \mathrm{C}$ for $30 \mathrm{~min}$, and then kept at $80^{\circ} \mathrm{C}$ to obtain a constant weight and were then weighed. Each treatment and control was repeated six times. Relative water content (RWC) of the shoots and roots were recorded by the method of Tian et al. (2015).

$$
\mathrm{RWC}(\%)=(\mathrm{FW}-\mathrm{DW}) / \mathrm{FW} \times 100
$$

Where RWC represents relative water content, FW represents fresh weight, and DW represents dry weight.

\section{Chlorophyll and Proline Content}

Chlorophyll was extracted with $80 \%(\mathrm{v} / \mathrm{v})$ cold acetone from all leaf segments $(200 \mathrm{mg})$, which were frozen at $-20^{\circ} \mathrm{C}$ after 15 days of $150 \mathrm{mM} \mathrm{NaCl}$ treatment. The content of chlorophyll a, chlorophyll b, and total chlorophyll in wheat seedling leaves were determined spectrophotometrically according to the method of Lichtenthaler (1987).

Proline content of leaves was determined following the procedure of Bates et al. (1973). After 15 days of $\mathrm{NaCl}$ treatment, $0.5 \mathrm{~g}$ of fresh wheat seedling leaf samples were homogenized with $10 \mathrm{ml}$ of $3 \%$ ASA. After that, $2 \mathrm{ml}$ of $\mathrm{AN}$ and $2 \mathrm{ml}$ of GAA were added to $2 \mathrm{ml}$ of the extract and mixed for $1 \mathrm{~h}$ at $100^{\circ} \mathrm{C}$. The reaction was then stopped by using an ice bath. The reaction mixture was extracted with $4 \mathrm{ml}$ toluene. The absorbance of fraction with toluene aspired from liquid phase was measured at $520 \mathrm{~nm}$. Proline concentration was determined by following a calibration curve and expressed as micromoles proline per gram of fresh weight. Each treatment was repeated for six times.

\section{Soluble Sugar and Protein Content}

All the collected leaf samples from the treatment and control were washed with distilled water three times and cut into small pieces to determine the content of soluble sugar and protein in wheat seedling leaves. Thereafter, the small pieces of wheat seedling leaves were dried, weighed, and placed separately in glass vials which contained $10 \mathrm{ml}$ of $80 \%(\mathrm{v} / \mathrm{v})$ ethanol, and then placed in a water bath heated at $60^{\circ} \mathrm{C}$ for $30 \mathrm{~min}$. The filtered extracts were diluted with $80 \%(\mathrm{v} / \mathrm{v})$ of ethanol to get a total volume of $20 \mathrm{ml}$. Soluble sugar concentration in the extract was determined by comparison with a standard curve using the criterion of glucose, as described by Giannakoula et al. (2008). Soluble protein content was carried out according to the method described by Bradford (1976). The coomassie brilliant blue G-250 reagent with BSA was regarded as a standard to determine the content of soluble protein in wheat seedling leaves.

\section{Root Activity and Lipid Peroxidation Degree}

Root activity was determined by TTC, as described by method with some modifications (Zhang et al., 2014a). Wheat seedling roots were washed, and then excised at $2 \mathrm{~cm}$ in length from the root tips 15 days after $\mathrm{NaCl}$ application. Root tips were dried with filter paper and homogenized with liquid nitrogen in an ice cold mortar and pestle. The reaction mixture consisted of $0.5 \mathrm{~g}$ samples of root tips, $5 \mathrm{ml}$ of PBS (pH 7.0), and $5 \mathrm{ml}$ of $0.4 \%$ TTC in a beaker, with root tips fully immersed in the solution for $1 \mathrm{~h}$ at $37^{\circ} \mathrm{C}$, then immediately mixed with $2 \mathrm{ml}$ of $1 \mathrm{M}$ sulfuric acid to stop the reaction. The red extraction was moved into a tube making the total volume $10 \mathrm{ml}$ using ethyl acetate. Thereafter, the extraction was added and vortexed for $30 \mathrm{~s}$ and centrifuged (1, $000 \mathrm{rpm}, 5 \mathrm{~min}$ ). The extraction was measured at $485 \mathrm{~nm}$ against a blank of ethyl acetate. The root activity of wheat seedlings was determined by measuring the activity of dehydrogenase, which present the function to reduce the chemical TTC. The analysis was repeated six times.

The concentration of MDA, a product of lipid peroxidation, was assessed by the method of TBA. The contents of MDA were determined following the method of Madhava Rao and Sresty (2000). Samples of fresh leaves $(0.5 \mathrm{~g})$ were homogenized in $10 \mathrm{ml}$ of $0.1 \%(\mathrm{w} / \mathrm{v})$ TCA. Then, $4 \mathrm{ml}$ of $0.5 \%(\mathrm{w} / \mathrm{v})$ TBA containing $20 \%(\mathrm{w} / \mathrm{v})$ TCA was added to $1 \mathrm{ml}$ aliquot of supernatant. The absorbance of the supernatant was recorded at 532 and $600 \mathrm{~nm}$ and MDA content was expressed as $1 \mu \mathrm{mol} \mathrm{MDA} \mathrm{g}{ }^{-1} \mathrm{FW}$. The content of TBARS was determined as described by Hodges et al. (1999). The concentration of TBARS was calculated based on the absorbance at 532 and $600 \mathrm{~nm}$. All the treatments and control were repeated six times.

\section{Antioxidant Enzymes Activities}

Antioxidant enzymes were extracted at $4^{\circ} \mathrm{C}$ using $0.5 \mathrm{~g}$ tissue from the fresh samples of wheat seedling leaves after 15 days of $\mathrm{NaCl}$ treatment. Fresh samples were homogenized with $5 \mathrm{ml}$ of extraction buffer, which contained $0.2 \mathrm{mM}$ EDTA, $0.1 \mathrm{M}$ phosphate buffer ( $\mathrm{pH} 7.8$ ) and $2 \%$ polyvinylpyrrolidone. Extracts were centrifuged at 10,000 rpm for $15 \mathrm{~min}$, and the supernatants 
were used for determining the activities of antioxidant enzymes. All the analysis was repeated six times.

Superoxide dismutase activity was measured as described by the method of Costa et al. (2002). One unit of SOD activity was defined as the amount of crude enzyme extract that inhibits the reduction of $\beta$-nitro blue tretrazolium chloride by the rate of $50 \%$ at $560 \mathrm{~nm}$ in the spectrophotometer.

Peroxidase activity was assayed by determining the increase of absorbance at $470 \mathrm{~nm}$ with guaiacol as the substrate (Kochba et al., 1977). The concentration of protein in the extracts was calculated and carried out as the method described by Lowry et al. (1951).

Catalase activity was assayed according to the method of Cakmak and Horst (1991) with some modifications. The activity of CAT was determined by calculating the decline decomposition of $\mathrm{H}_{2} \mathrm{O}_{2}$ in absorbance at $240 \mathrm{~nm}$.

\section{Extraction of Total RNA and Analysis of Gene Expression by Quantitative Real Time Reverse Transcriptase-PCR (qRT-PCR)}

Total RNA was extracted from different treatment of the wheat seedlings leaves $(0.2 \mathrm{~g})$ by using PureLink ${ }^{\circledR}$ RNA Mini Kit (Tiangen Biotechnology, Beijing, China). The quality of total RNA was quantified by the UV spectrophotometer. Firststrand cDNA was synthesized by Revert Aid TM First Strand cDNA Synthesis Kit (Tiangen Biotechnology, Beijing, China). The qRT-PCR was performed in a $20 \mu \mathrm{l}$ reaction volume tube using the SYBR ExScript qRT-PCR Kit (Takara, Dalian, China) according to the method described previously by $\mathrm{Li}$ et al. (2013) and Qiu et al. (2013). Specific primers for SOD, POD, and CAT genes, and the internal control tubulin gene were used to amplify amplicons specific for wheat seedlings. Specific primers were designed according to wheat EST sequences of candidate proteins available in NCBI (Qiu et al., 2014; Zou et al., 2015), and the DNA sequences of specific primers are provided in Table 1. Melting curve analysis of amplification products was performed at the end of each PCR to confirm that only one PCR product was amplified and detected. Gene expression was counted and expressed relative to the expression levels of an internal reference gene actin in each sample using the $2^{-\Delta \Delta C t}$ method (Livak and Schmittgen, 2001).

\section{Statistical Analysis}

The data was subject to one-way ANOVA using the SPSS package (SPSS V16.0, SPSS, Inc., Chicago, IL, USA). Treatment effects were determined using Duncan's multiple range test and the significances were expressed at $P<0.05$.

\section{RESULTS}

\section{Plant Growth and Relative Water Content}

Fifteen days after $\mathrm{NaCl}$ treatment, the wheat seedling height (Figure 1A) and root length (Figure 1B) were significantly
TABLE 1 | DNA sequences of qRT-PCR primers for determining the antioxidant gene expressed in wheat seedlings under salt stress.

\begin{tabular}{|c|c|c|}
\hline $\begin{array}{l}\text { Gene } \\
\text { names }\end{array}$ & $\begin{array}{c}\text { Accession } \\
\text { number }\end{array}$ & Premiers sequence $\left(5^{\prime}-3^{\prime}\right)$ \\
\hline \multirow[t]{2}{*}{ Actin } & AB181991 & Forward: CTCTGACAATTTCCCGCTCA \\
\hline & & Reverse: ACACGCTTCCTCATGCTATCC \\
\hline \multirow[t]{2}{*}{ SOD } & JQ613154.1 & Forward: CATTGTCGATAGCCAGATTCCTTा \\
\hline & & Reverse: AGTCTTCCACCAGCATTTCCAGTA \\
\hline \multirow[t]{2}{*}{ POD } & X53675.1 & Forward: CAGCCCTGTAGCCAACATAAA \\
\hline & & Reverse: GCACTTCCACGACTGCTTTG \\
\hline \multirow[t]{2}{*}{ CAT } & GU984379.1 & Forward: TTTGATGGGAGTCTTGTGCTTGTG \\
\hline & & Reverse: ACGGTGAGGGAGTTGTCGTTGTT \\
\hline
\end{tabular}

reduced compared to the control, while the application of the plant-growth-promoting fungi T6 significantly increased wheat seedling height and root length, compared to the $\mathrm{NaCl}$ stress treatment. Compared to the control, T6 promoted wheat seedling growth after 15 days without $\mathrm{NaCl}$ treatment.

The plant-growth-promoting fungi T6 showed a great ability to colonize the roots of wheat seedlings. Compared to the control and $\mathrm{NaCl}$ treatments alone, colonies of T6 were re-isolated from the wheat roots, regardless of whether or not the wheat seeds were soaked with the suspension of T6 under salt stress (Table 2). In contrast, there were no colonies re-isolated from the roots in the control or $\mathrm{NaCl}$ treatments alone. These observations indicated that the strain of T6 had the ability to colonize the roots of wheat seedlings under salt stress.

The concentration of $150 \mathrm{mM}$ of $\mathrm{NaCl}$ stress decreased wheat seedling growth. The shoot height and root length decreased by 17 and 16\%, respectively, compare to the control (Table 2). The shoot and root fresh weights decreased by 33 and $26 \%$, and dry weights decreased by 15 and $19 \%$, respectively, compared to the control (Table 3). However, compared to NaCl-stressed plants, the shoot height and root length increased by 15 and 34\%, respectively, in plants after being treated with T6 under salt stress (Table 2). Also, the shoot and root fresh weights increased by 23 and $22 \%$, and dry weights increased by 10 and $24 \%$, respectively (Table 3).

Compared to the control, the RWC of shoots and roots were lower for the plants treated with $150 \mathrm{mM}$ of $\mathrm{NaCl}$ stress alone, but inversely, the application of T6 significantly increased the water content in wheat shoots and roots (Table 3 ).

\section{Chlorophyll and Proline Content}

Chlorophyll a, chlorophyll b, and total chlorophyll contents were decreased by 15,17 , and $15 \%$, respectively, when treated with $150 \mathrm{mM}$ of $\mathrm{NaCl}$, compared to the control. However, the leaf chlorophyll a, b, and total chlorophyll contents in $\mathrm{NaCl}$-stressed wheat seedlings were reversed to a similar level as the control, after being treated with T6. Leaf chlorophyll contents were lower in the plants under salt stress without T6. Also, compared to the control, the values of chlorophyll a, b, and total chlorophyll contents were increased significantly with the application of T6 without salt stress (Table 4). 


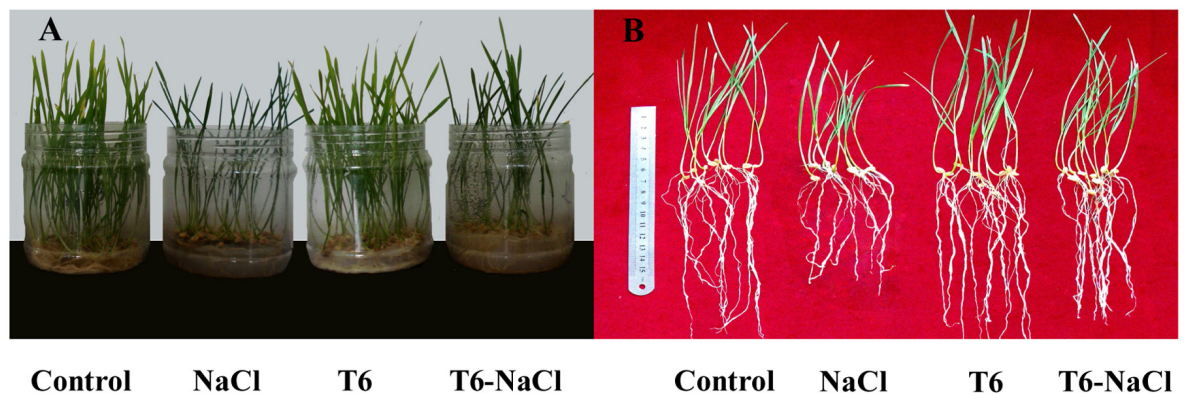

FIGURE 1 | Effect of salt stress and Trichoderma longibrachiatum T6 treatments on (A) wheat seedling growth and (B) wheat root length. The treatment names are detailed in the footnote of Table 2.

TABLE 2 | Effects of Trichoderma longibrachiatum T6 on number of colonies in wheat roots and plant growth traits under salt stress.

\begin{tabular}{|c|c|c|c|}
\hline \multirow[t]{2}{*}{ Treatments } & \multirow{2}{*}{$\begin{array}{l}\text { Colony densities } \\
\text { [CFU } \mathrm{g}^{-1} \text { of root } \\
\left.\qquad\left(\times 10^{5}\right)\right]\end{array}$} & \multicolumn{2}{|c|}{ Plant growth parameters } \\
\hline & & $\begin{array}{l}\text { Plant height } \\
\left(\mathrm{cm} \mathrm{plant}^{-1}\right)\end{array}$ & $\begin{array}{l}\text { Root length } \\
\left(\mathrm{cm} \text { plant }^{-1}\right)\end{array}$ \\
\hline Control & $0.00 \pm 0.00 c$ & $13.30 \pm 0.50 b$ & $12.14 \pm 0.78 \mathrm{bc}$ \\
\hline $\mathrm{NaCl}$ & $0.00 \pm 0.00 \mathrm{c}$ & $11.03 \pm 0.58 c$ & $10.18 \pm 0.59 c$ \\
\hline T6 & $5.40 \pm 0.47 a$ & $15.23 \pm 0.59 \mathrm{a}$ & $14.34 \pm 0.49 a$ \\
\hline $\mathrm{T} 6-\mathrm{NaCl}$ & $4.46 \pm 0.36 b$ & $12.70 \pm 0.61 \mathrm{bc}$ & $13.62 \pm 0.64 \mathrm{ab}$ \\
\hline
\end{tabular}

Mean \pm standard error of replicates in a column followed by different letters are significantly different based on Duncan's multiple range test at $P<0.05$ $(n=12)$. Control represents wheat seedlings grown under normal condition; $\mathrm{NaCl}$ represents wheat seedlings stressed under $150 \mathrm{mM} \mathrm{NaCl}$; T6 represents wheat seeds pretreated with $\mathrm{T6}$ for $12 \mathrm{~h}$ before planting without $\mathrm{NaCl}$ treatment; T6$\mathrm{NaCl}$ represents wheat seeds pretreated with $\mathrm{T} 6$ for $12 \mathrm{~h}$ before planting and then stressed under $150 \mathrm{mM}$ of $\mathrm{NaCl}$.

Compared to the control, the proline content was significantly increased in wheat seedling leaves, after being treated with $150 \mathrm{mM}$ of $\mathrm{NaCl}$ solution or with the T6 strain. The highest increase of proline was presented in wheat plants pretreated with T6 under $150 \mathrm{mM} \mathrm{NaCl}$ stress, which increased by 35\% in leaves with $\mathrm{NaCl}$ treatment for 15 days, compared to $\mathrm{NaCl}$-stressed plants (Table 4).

\section{Soluble Sugar and Protein Content}

Application of T6 increased the soluble sugar and protein contents in the wheat seedlings grown under salt stress or nonsaline stress, compared to the control. However, the content of soluble sugar and protein in wheat seedlings significantly decreased after the treatment of $\mathrm{NaCl}$ alone (Table 4). In the wheat leaves, the content of soluble sugar and protein decreased by 15 and $18 \%$ after the $\mathrm{NaCl}$ treatment alone compared to the control, but they increased by 41 and $46 \%$ when treated with T6 alone, and increased by 31 and 35\%, respectively, when treated with T6 in combination with $150 \mathrm{mM}$ of $\mathrm{NaCl}$, compare to the NaCl-stressed plants. These results showed the application of T6 increased the contents of soluble sugar and protein in wheat seedlings, with the effect on the soluble protein content being greater than the effect on soluble sugar content (Table 4).

\section{Root Activity and Lipid Peroxidation Degree Detection}

The root activity of wheat seedlings significantly decreased under salt stress. The root activity decreased by $20 \%$ in wheat seedlings treated with $150 \mathrm{mM}$ of $\mathrm{NaCl}$, while the root activity significantly increased after the seedlings were treated with T6 or T6 plus $150 \mathrm{mM}$ of $\mathrm{NaCl}$. T6 had a high effect on the root activity whether the wheat seedlings were under salt stress or non-saline stress (Table 5).

Malondialdehyde, a product of lipid peroxidation, is generally regarded as an indicator of free radical damage to cell membranes caused by oxidative stress. Wheat seedlings inoculated with $150 \mathrm{mM}$ of $\mathrm{NaCl}$ and without $\mathrm{T} 6$ increased the MDA content in leaves by $50 \%$, compared to the control. However, the seedlings inoculated with the strain of T6 had high efficiency in decreasing the content of MDA under salt stress, compared to $\mathrm{NaCl}$-stressed plants. Thus, the content of MDA decreased by 45 and $15 \%$ in T6 alone and T6 plus $\mathrm{NaCl}$ treated plants, respectively, compared to $\mathrm{NaCl}$-stressed plants (Table 5).

\section{Antioxidant Enzymes Detection}

Salt stress significantly induced and increased the antioxidant enzymes activities in wheat seedlings, including the activities of SOD, POD, and CAT (Figure 2). Also, the activities of SOD, POD, and CAT were significantly increased after being treated with T6 under salt stress or non-saline stress, compared to the control and the $\mathrm{NaCl}$-stressed plants. Moreover, the application of T6 significantly increased the activities of SOD (Figure 2A), POD (Figure 2B), and CAT (Figure 2C) either in the control group or in the $\mathrm{NaCl}$-stressed wheat seedling leaves; in the control, these values increased by 13,12 , and $14 \%$, respectively; in the $\mathrm{NaCl}$-stressed plants, these values increased by 29,39 , and $19 \%$, respectively, compared to the $\mathrm{NaCl}$ treatment alone. The activities of SOD, POD, and CAT were greater with the addition of $\mathrm{T} 6$ in the $\mathrm{NaCl}$-stressed plants, compared to the control plants with T6. The activity of CAT in seedlings treated with T6 alone did not differ from seedlings treated with $\mathrm{T} 6$ plus $\mathrm{NaCl}$ stress treatment, whereas the activities of SOD and POD differed significantly between the two treatments. 
TABLE 3 | Effects of T. longibrachiatum T6 on wheat seedling weight and relative water content under salt stress.

\begin{tabular}{|c|c|c|c|c|c|c|}
\hline \multirow[t]{2}{*}{ Treatments } & \multicolumn{3}{|c|}{ Wheat shoot } & \multicolumn{3}{|c|}{ Wheat root } \\
\hline & $\begin{array}{l}\text { Fresh weight } \\
\left.\text { (g plant }^{-1}\right)\end{array}$ & $\begin{array}{l}\text { Dry weight } \\
\text { (g plant }^{-1} \text { ) }\end{array}$ & $\begin{array}{c}\text { Relative water } \\
\text { content (\%) }\end{array}$ & $\begin{array}{l}\text { Fresh weight } \\
\left.\text { (g plant }^{-1}\right)\end{array}$ & $\begin{array}{l}\text { Dry weight } \\
\text { (g plant }^{-1} \text { ) }\end{array}$ & $\begin{array}{c}\text { Relative water } \\
\text { content }(\%)\end{array}$ \\
\hline Control & $0.271 \pm 0.02 b$ & $0.048 \pm 0.003 \mathrm{ab}$ & $82.16 \pm 0.53 a$ & $0.121 \pm 0.006 \mathrm{~b}$ & $0.021 \pm 0.001 b$ & $82.61 \pm 0.67 \mathrm{ab}$ \\
\hline $\mathrm{NaCl}$ & $0.182 \pm 0.01 d$ & $0.041 \pm 0.001 b$ & $77.75 \pm 0.76 c$ & $0.089 \pm 0.003 c$ & $0.017 \pm 0.002 c$ & $80.65 \pm 0.47 b$ \\
\hline T6 & $0.299 \pm 0.02 \mathrm{a}$ & $0.054 \pm 0.004 \mathrm{a}$ & $82.00 \pm 0.47 \mathrm{a}$ & $0.136 \pm 0.004 \mathrm{a}$ & $0.023 \pm 0.002 \mathrm{a}$ & $83.01 \pm 0.59 \mathrm{a}$ \\
\hline T6- $\mathrm{NaCl}$ & $0.224 \pm 0.01 c$ & $0.045 \pm 0.002 \mathrm{ab}$ & $80.08 \pm 0.30 b$ & $0.109 \pm 0.006 b$ & $0.021 \pm 0.001 b$ & $81.27 \pm 0.64 a b$ \\
\hline
\end{tabular}

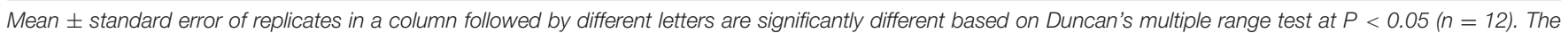
treatment names are detailed in the footnote of Table 2.

TABLE 4 | Effects of T. longibrachiatum T6 on the contents of chlorophyll, proline, soluble sugar, and protein in wheat seedlings under salt stress.

\begin{tabular}{|c|c|c|c|}
\hline Treatments & $\begin{array}{l}\text { Chlorophyll } \\
\text { a content } \\
\left(\mathbf{m g ~ g}^{-1}\right)\end{array}$ & $\begin{array}{l}\text { Chlorophyll } \\
\text { b content } \\
\left(\mathbf{m g ~ g}^{-1}\right)\end{array}$ & $\begin{array}{c}\text { Total chlorophyll } \\
\text { content } \\
\left(\mathrm{mg} \mathrm{g}^{-1}\right)\end{array}$ \\
\hline \multicolumn{4}{|c|}{ Effect on chlorophyll } \\
\hline Control & $1.44 \pm 0.09 b$ & $0.48 \pm 0.06 c$ & $1.92 \pm 0.15 b$ \\
\hline $\mathrm{NaCl}$ & $1.23 \pm 0.13 c$ & $0.40 \pm 0.11 c$ & $1.63 \pm 0.11 c$ \\
\hline T6 & $1.59 \pm 0.12 \mathrm{a}$ & $0.56 \pm 0.08 \mathrm{a}$ & $2.16 \pm 0.20 a$ \\
\hline $\mathrm{T} 6-\mathrm{NaCl}$ & $1.42 \pm 0.16 b$ & $0.54 \pm 0.10 b$ & $1.96 \pm 0.21 b$ \\
\hline Treatments & $\begin{array}{c}\text { Proline } \\
\left.(\mu \mathrm{mol} \mathrm{g})^{-1} \mathrm{FW}\right)\end{array}$ & $\begin{array}{c}\text { Soluble } \\
\text { sugar }\left(\mathrm{mg} \mathrm{g}^{-1}\right)\end{array}$ & $\begin{array}{c}\text { Soluble } \\
\text { protein }\left(\mathrm{mg} \mathrm{g}^{-1}\right)\end{array}$ \\
\hline \multicolumn{4}{|c|}{ Effect on proline, soluble sugar, and protein } \\
\hline Control & $15.23 \pm 0.29 c$ & $20.58 \pm 0.42 c$ & $15.58 \pm 0.41 b$ \\
\hline $\mathrm{NaCl}$ & $20.40 \pm 0.44 b$ & $17.44 \pm 0.35 d$ & $12.74 \pm 0.64 c$ \\
\hline T6 & $22.17 \pm 0.93 b$ & $24.54 \pm 0.67 \mathrm{a}$ & $18.56 \pm 0.62 \mathrm{a}$ \\
\hline T6-NaCl & $27.63 \pm 1.05 \mathrm{a}$ & $22.85 \pm 0.40 b$ & $17.25 \pm 0.84 a b$ \\
\hline
\end{tabular}

Data are mean \pm standard error of replicates in a column followed by different letters are significantly different at $P<0.05(n=12)$, based on Duncan's multiple range test using one-way ANOVA. The treatment names are detailed in the footnote of Table 2.

\section{The Level of SOD, POD, and CAT Gene Expression}

Compared to the control plants, there were higher levels of SOD, POD, and CAT gene expression in wheat seedlings after being induced by $\mathrm{NaCl}$ stress (Figure 3). With the $\mathrm{T} 6$ treatment, the gene expression of the SOD (Figure 3A), POD (Figure 3B), and CAT (Figure 3C) were significantly up-regulated whether or not the wheat seedlings were treated with $\mathrm{NaCl}$ stress, compared to the control. In contrast, there were no significant differences in the expression levels of the SOD genes in the treatment of the $\mathrm{NaCl}$ stress alone or $\mathrm{T} 6$ alone (Figure 3A).

\section{DISCUSSION}

Previous studies have demonstrated that a high level of salinity is one of the major environmental stress factors that causes biochemical alterations in plants, limits plant growth, and decreases plant productivity (Allakhverdiev et al., 2000; Mahmood et al., 2012). Trichoderma species are one of the most
TABLE 5 | Effect of $T$. longibrachiatum T6 on the root activity and MDA content of wheat seedlings under salt stress.

\begin{tabular}{lcc}
\hline Treatments & $\begin{array}{c}\text { Root activity } \\
\left(\boldsymbol{\mu} \mathbf{g ~ g}^{-\mathbf{1}} \mathbf{h}^{-\mathbf{1}} \mathbf{)}\right.\end{array}$ & $\begin{array}{c}\text { MDA content } \\
\left(\boldsymbol{\mu} \mathbf{m o l ~} \mathbf{~ g}^{-1} \mathbf{F W}\right)\end{array}$ \\
\hline Control & $225.44 \pm 6.45 \mathrm{~b}$ & $16.79 \pm 0.31 \mathrm{c}$ \\
$\mathrm{NaCl}$ & $179.56 \pm 8.71 \mathrm{C}$ & $25.12 \pm 1.12 \mathrm{a}$ \\
$\mathrm{T} 6$ & $259.84 \pm 8.11 \mathrm{a}$ & $13.87 \pm 1.15 \mathrm{C}$ \\
$\mathrm{T} 6-\mathrm{NaCl}$ & $242.46 \pm 10.43 \mathrm{ab}$ & $21.37 \pm 0.52 \mathrm{~b}$ \\
\hline
\end{tabular}

Data are mean \pm standard error of replicates in a column followed by different letters are significantly different at $P<0.05(n=12)$, based on Duncan's multiple range test using one-way ANOVA. The treatment names are detailed in the footnote of Table 2 .

versatile opportunistic plant symbionts which can colonize plant roots (Brotman et al., 2013). These symbionts are well-known for their remarkable interactions with host plants and their ability to induce broad-spectrum resistance to plant pathogens (Naseby et al., 2000; Yedidia et al., 2003; Harman et al., 2004). Although, the plant-growth-promoting capability of Trichoderma spp. has been previously reported, there is little information concerning plants' systemic responses induced by T6 under salt stress conditions. Our results demonstrated that the $\mathrm{NaCl}$ treatment significantly inhibited wheat seedling growth and development after 15 days and the effect was alleviated substantially with the application of T6. To the best of our knowledge, the present study is the first to discover the role of plant-growth-promoting fungi T6 in enhancing the tolerance of wheat seedlings to salt stress. Also, our study determined the possible mechanism of how plantgrowth-promoting fungi $\mathrm{T} 6$ alleviated the negative effect of $\mathrm{NaCl}$ stress in wheat seedlings. The use of T6 enhanced the tolerance of wheat seedlings to salt stress at physiological and molecular levels.

Shoresh et al. (2010) reported that host roots colonized by Trichoderma strains enhanced whole-plant tolerance to biotic and abiotic stresses. The enhancement was indicated by increased plants root growth and nutritional status (Harman et al., 2000), and induced systemic resistance to diseases (Harman et al., 2004). In the present study, we found that $\mathrm{T} 6$ has a great ability to colonize the roots of wheat seedlings under salt stress, which significantly improved wheat seedlings growth and development under salt stress. Bae et al. (2009) showed that cacao (Theobroma cacao) seedlings which were colonized by Trichoderma hamatum isolate DIS 219b enhanced seedling growth and development. In 

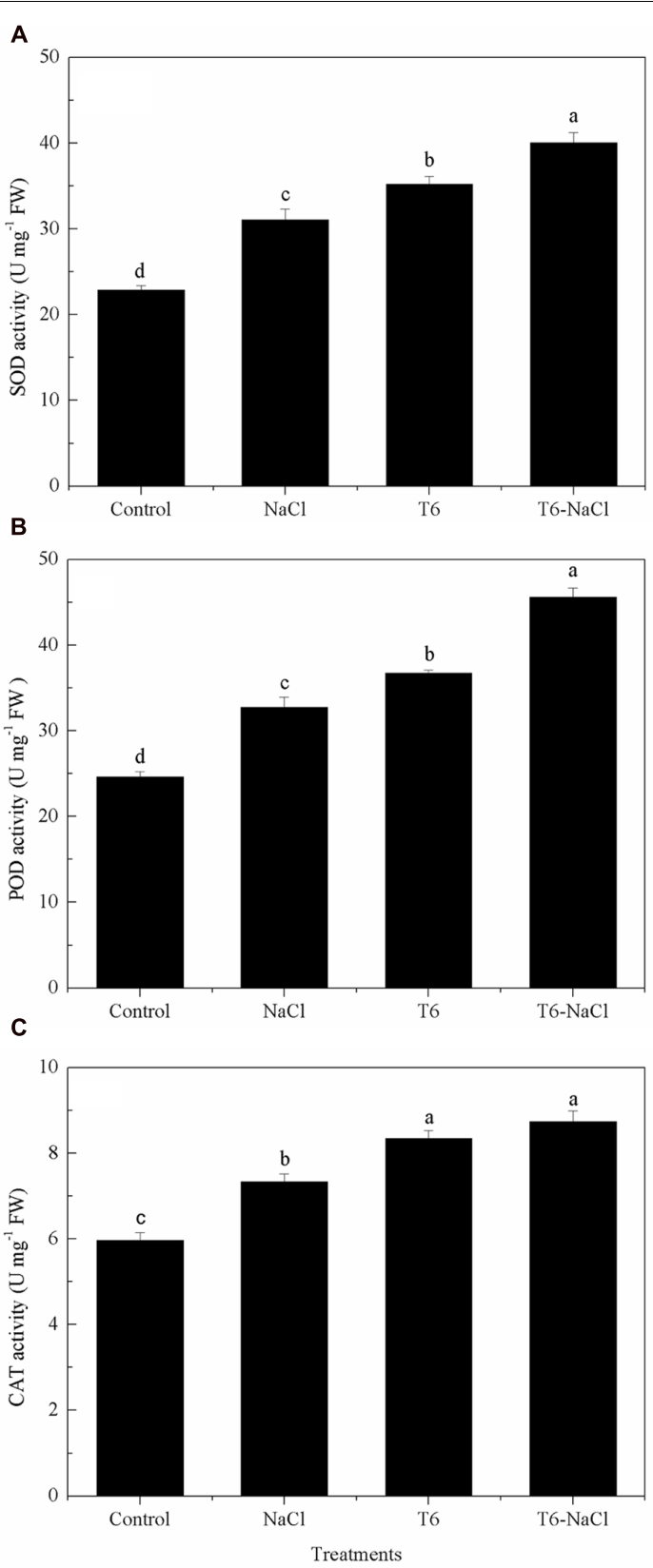

FIGURE 2 | Effect of T. longibrachiatum T6 treatment on the activity of (A) SOD, (B) POD, and (C) CAT in the leaves of wheat seedlings under salt stress. Small bars represent the standard errors of the means $(n=12)$. Different lowercase letters indicate significant differences at $P<0.05$ in Duncan's multiple range test using one-way ANOVA. The treatment names are detailed in the footnote of Table 2. a similar study, Adams et al. (2007) found that the plant saplings grown with $T$. afroharzianum $\mathrm{T} 22$ produced more biomass than non-inoculated controls in metal contaminated soil. Our findings are supported by a number of previous observations where Trichoderma spp. has the ability to colonize plant roots, establish symbiotic relationships with a wide range of host plants, and promote plant growth and development (Shoresh et al.,
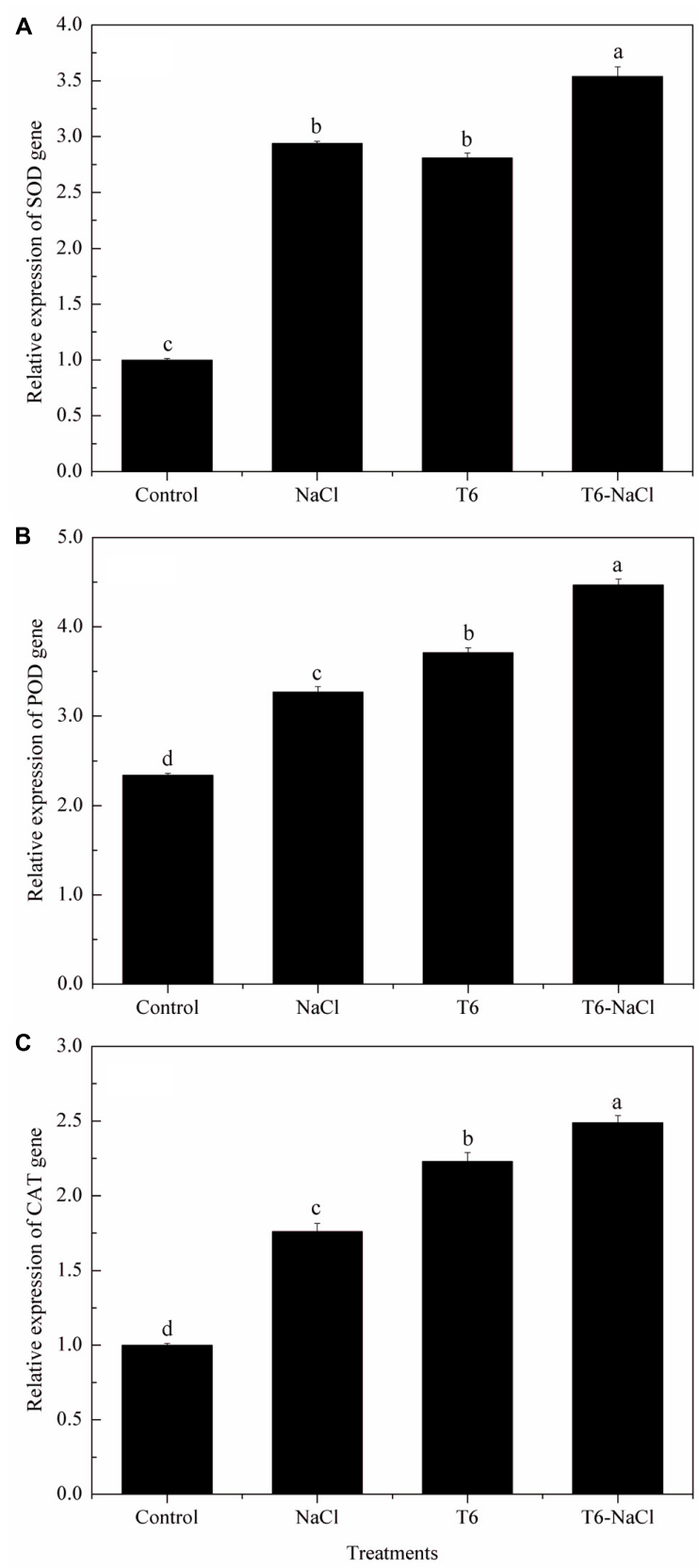

FIGURE 3 | Effect of T. longibrachiatum T6 on the genes of (A) SOD, (B) POD, and (C) CAT expression in the leaves of wheat seedlings under salt stress. Small bars represent the standard errors of the means $(n=12)$. Different lowercase letters indicate significant differences at $P<0.05$ in Duncan's multiple range test using one-way ANOVA. The treatment names are detailed in the footnote of Table 2.

2010; Harman, 2011). Moreover, similar results were reported that Trichoderma parareesei increased the tomato lateral root development and growth promotion under salt stress conditions (Rubio et al., 2014).

Chlorophyll content is widely used as an indicator of abiotic tolerance in plants. Singh and Gautam (2013) reported that plants 
exposed to salinity stressful environments decreased chlorophyll concentration, leading to overall growth retardation. In the present study, we found that $\mathrm{NaCl}$-induced stress significantly decreased chlorophyll content in wheat seedlings, but chlorophyll content was reversed back to a similar level as the control in wheat seedlings treated with T6. Similar results were reported in $\mathrm{NaCl}$-stressed soybean (Glycine max) and cotton (Gossypium spp.) seedlings by other researchers (Simaei et al., 2011; Liu et al., 2014). Tariq et al. (2011) found the oxidation of chlorophyll and chloroplast pigments, as well as the instability of the pigment protein complex in salt stress conditions were the possible reasons for the decrease of chlorophyll content in salinitystressed wheat seedling leaves. However, we discovered that the content of chlorophyll significantly increased in wheat seedlings with the application of T6 whether or not the seedlings were subjected to salt stress. The latter application may inhibit the production and accumulation of ROS in plant tissue. Similar results were reported in NaCl-treated cucumber (Cucumis sativus) seedlings (Qi et al., 2012).

Plant roots are critical for plant growth and development which is attributed to their function and importance in absorption of nutrients and water from soil (Qi et al., 2012). We found $\mathrm{NaCl}$ stress had a high effect on the wheat root growth and development, and that salt treatment significantly decreased the root activity. However, the root activity was significantly increased when the plant-growth-promoting fungi T6 was applied to the wheat seedlings either under salt stress or non-saline conditions. A similar phenomenon was found in our previous studies where the strain of $T$. longibrachiatum significantly increased the root activity after wheat seedlings were infected with $H$. avenae, a plant parasitic nematode (Zhang et al., 2014a).

In the present study, the content of proline was increased in wheat seedling grown with $\mathrm{NaCl}$ alone, compared to the control. The results from the previous research indicated that the increased level of proline in plants under salt stress condition may have been due to the activation of proline biosynthesis which enhances protein turnover (Khan et al., 2010). Proline is an important nitrogen source that is available for plant recovery from environmental stress and restoration of growth (Trotel et al., 1996), and it can act as an osmolyte that reduces the osmotic potential of the cell and the uptake of toxic ions (Woodward and Bennett, 2005). Thus, proline plays a predominant role in protecting plants from osmotic stress (Khan et al., 2010). An added value from the present study is that the use of the plant-growth-promoting fungi T6 can significantly increase the proline content in wheat seedlings under salt or nonsaline stress. Alleviating effects of oligochitosan on salt stressinduced oxidative damage in wheat leaves might be related to its regulation roles in proline levels. In addition, the results from our study indicated that the content of MDA significantly increased in $\mathrm{NaCl}$-stressed wheat seedlings in comparison to the control plants, which is consistent with the findings of Seckin et al. (2008) in wheat. Thereafter, the content of MDA significantly decreased after wheat seeds were soaked in the suspension of T6 before $\mathrm{NaCl}$ stress. Taken together, our results are consistent with data from Rawat et al. (2011), who demonstrated that wheat seed biopriming with salinity-tolerant isolates of $T$. harzianum Th-14, Th-19, and Th-13 reduced the accumulation of MDA content, whereas, it increased the proline content in wheat seedlings under both salt and non-saline conditions.

It is widely accepted that osmosis molecules, including soluble sugars and proteins, are important indicators in response to abiotic stress (Azevedo-Neto et al., 2006). The increased accumulation of glucose and sucrose in plants usually indicates a highly protective mechanism against oxidative damage caused by high salinity in the plant environment (Murakeozy et al., 2003; Bartels and Sunkar, 2005). However, most previous studies determined the physiologic role of soluble sugars and utilization by plants. We found that T6 had a highly significant effect on the content of soluble sugar and protein in wheat seedlings either under salt stress or non-saline conditions.

In plants, the overproduction of ROS is considered a biochemical change under salt stress (Younis et al., 2010), which is the most important factor responsible for $\mathrm{NaCl}$ induced damage to macromolecules and plants cellular structures (Özdemir et al., 2004). To alleviate the damage associated with the overproduction of ROS, plants have naturally developed a wide range of enzymatic defense mechanisms to detoxify free radicals and thereby help protect themselves from destructive oxidative damage (Parida et al., 2004; Li et al., 2011). One of the important protective mechanisms in plants is the enzymatic antioxidant system, which involves the simultaneous action of a number of enzymes including SOD, POD, and CAT (Ma et al., 2012). The findings from the present study demonstrate that $\mathrm{NaCl}$ stress induced plants produce a higher level of SOD, POD, and CAT activity in wheat seedlings than the control samples. However, the use of T6 increased SOD, POD, and CAT activity in wheat seedlings regardless of salt concentration, which was in accordance with the findings of Ahmad et al. (2015), who demonstrated that the role of T. harzianum in Indian mustard (Brassica juncea) was to mitigate $\mathrm{NaCl}$ stress by an antioxidative defense system. Our results suggested that the coordination of POD and CAT activity along with SOD activity played a central protective role in the $\mathrm{O}_{2}{ }^{-}$and $\mathrm{H}_{2} \mathrm{O}_{2}$ scavenging process in wheat seedlings treated with $\mathrm{T} 6$. Also, we suggested that the strain of $\mathrm{T} 6$ had better $\mathrm{O}_{2}{ }^{-}$and $\mathrm{H}_{2} \mathrm{O}_{2}$ scavenging ability than the control in protecting the plants from oxidative damage.

Some plant-beneficial fungi Trichoderma species can induce profound impacts or changes in different species of plant gene expression under biotic and abiotic stresses (Mastouri et al., 2010). Increased SOD activity in stressed plants may be attributed to the significantly increased level of ROS, which causes an increase of gene expression responsible for encoding the activity of SOD (Bowler et al., 1992; Shekhawat et al., 2010). Therefore, in the present study, we firstly determined the effect T6 might have had on the expression of antioxidant enzyme genes (SOD, POD, and CAT). We found that the change in expression for the genes of SOD, POD, and CAT had resulted in increased transcription levels which were in accordance with the increase of SOD, POD, and CAT activity; these increases coincided with the trend of the activities of the corresponding enzymes. A number of previous studies have also demonstrated that there is a higher level of gene family expression for genes involved in plant 
protection against abiotic stresses (Bailey et al., 2006; Alfano et al., 2007) in Trichoderma spp. pretreated plants. However, there are no in-depth studies on specific gene expression of wheat seedlings treated with plant-growth-promoting fungi T6. Meanwhile, we have confirmed that ROS generation under salt stress is followed by increased transcription and activity of ROS-scavenging enzymes in T6-challenged wheat plants, which indicated that the important role of ROS was detoxifying cellular survival and regulating plant acclimation (Miller et al., 2010). In addition, ROS also served as a critical signaling molecule in cell proliferation and survival. Similar results have been reported that salinity is one of the environment factors that can change the normal homeostasis of plant cells, and causes an increased production of ROS within plants. The ROS molecule functions as a toxic by-product of stress metabolism and is important in signaling transduction molecules in response to salt stress (Miller et al., 2010).

\section{CONCLUSION}

In summary, our results indicated that the strain of plantgrowth-promoting fungi T6 has a remarkable effect on alleviating the adverse effects of salt stress on wheat seedling growth and development. Multiple tests employed in the study allowed us to explore the possible mechanisms at a physiological and molecular level in which T6 provides the ability of alleviating the suppression effect of salt stress. The mechanisms may include (i) T6 increasing the activity of antioxidative defense system

\section{REFERENCES}

Adams, P., De-Leij, F. A., and Lynch, J. M. (2007). Trichoderma harzianum Rifai 1295-22 mediates growth promotion of crack willow (Salix fragilis) saplings in both clean and metal contaminated soil. Microb. Ecol. 54, 306-313. doi: 10.1007/s00248-006-9203-0

Ahmad, P., Hashem, A., Abd-Allah, E. F., Alqarawi, A. A., John, R., Egamberdieva, D., et al. (2015). Role of Trichoderma harzianum in mitigating $\mathrm{NaCl}$ stress in Indian mustard (Brassica juncea L) through antioxidative defense system. Front. Plant Sci. 6:868. doi: 10.3389/fpls.2015.00868

Alfano, G., Ivey, M. L. L., Cakir, C., Bos, J. I. B., Miller, S. A., Madden, L. V., et al. (2007). Systemic modulation of gene expression in tomato by Trichoderma hamatum 382. Phytopathololgy 97, 429-437. doi: 10.1094/PHYTO-974-0429

Allakhverdiev, S. I., Sakamoto, A., Nishiyama, Y., Inaba, M., and Murata, N. (2000). Ionic and osmotic effects of $\mathrm{NaCl}$ induced inactivation of photosystems I and II in Synechococcus sp. Plant Physiol. 123, 1047-1056. doi: 10.1104/pp.123.3.1047

Azevedo-Neto, A. D., Prisco, J. T., Enéas-Filho, J., Abreu, C. E. B., and GomesFilho, E. (2006). Effect of salt stress on antioxidative enzymes and lipid peroxidation in leaves and roots of salt-tolerant and salt-sensitive maize genotypes. Environ. Exp. Bot. 56, 87-94. doi: 10.1016/j.envexpbot.2005.01.008

Bae, H., Sicher, R. C., Kim, M. S., Kim, S. H., Strem, M. D., Melnick, R. L., et al. (2009). The beneficial endophyte Trichoderma hamatum isolate DIS 219b promotes growth and delays the onset of the drought response in Theobroma cacao. J. Exp. Bot. 60, 3279-3295. doi: 10.1093/jxb/erp165

Bailey, B. A., Bae, H., Strem, M. D., Roberts, D. P., Thomas, S. E., Crozier, J., et al. (2006). Fungal and plant gene expression during the colonization of cacao seedlings by endophytic isolates of four Trichoderma species. Planta 224, 1449-1464. doi: 10.1007/s00425-006-0314-0

Bartels, D., and Sunkar, R. (2005). Drought and salt tolerance in plants. Crit. Rev. Plant Sci. 24, 23-58. doi: 10.1080/07352680590910410 in wheat seedlings to resist salt stress, and (ii) enhancing the relative levels of antioxidant gene expression in the stressed plants. However, there are some issues that need to be addressed in future studies, such as the efficacy of the strain of plant-growthpromoting fungi T6 interactions with other plant species and other abiotic stresses. More detailed studies may be necessary to determine which compound plays the signaling role in T6 that induces systemic changes in the expression of encoding antioxidant enzymes and genes.

\section{AUTHOR CONTRIBUTIONS}

SZ and YG conceived and designed the experiments with the help of BX. SZ performed most of the salt treatment experiments and prepared the wheat RNA samples. YG and SZ performed qRTPCR and analyzed the data, with the help of BX. SZ and YG wrote the manuscript. SZ, YG, and BX revised and approved the final manuscript.

\section{ACKNOWLEDGMENTS}

This work was supported by Fostering Foundation for the Excellent Ph.D. Dissertation of Gansu Agricultural University (project YBPY2014002); International Scientific and Technological cooperation of Gansu Province (project 1604WKCA010) and Hall of Gansu Province Farming Herd Biology Technology (project GNSW-2013-19).

Bates, L. S., Waldren, R. P., and Teare, I. D. (1973). Rapid determination of free proline for water-stress studies. Plant Soil 39, 205-207. doi: 10.1007/BF00018060

Bowler, C., Van Montagu, M., and Inze, D. (1992). Superoxide dismutase and stress tolerance. Annu. Rev. Plant Physiol. Plant Mol. Biol. 43, 83-116. doi: 10.1146/annurev.pp.43.060192.000503

Bradford, M. M. (1976). A rapid and sensitive method for the quantitation of microgram quantities of protein utilizing the principle of protein-dye binding. Anal. Biochem. 72, 248-254. doi: 10.1016/0003-2697(76)90527-3

Brotman, Y., Landau, U., Cuadros-Inostroza, A., Takayuki, T., Fernie, A. R., Chet, I., et al. (2013). Trichoderma-plant root colonization: escaping early plant defense responses and activation of the antioxidant machinery for saline stress tolerance. PLoS Pathog. 9:e1003221. doi: 10.1371/journal.ppat.1003221

Bui, E. N. (2013). Soil salinity: a neglected factor in plant ecology and biogeography. J. Arid Environ. 92, 14-25. doi: 10.1016/j.jaridenv.2012.12.014

Cakmak, I., and Horst, W. J. (1991). Effect of aluminum on lipid peroxidation, superioxide dismutase, catalase, and peroxidase activities in root tips of soybean (Glycine max). Physiol. Plant 83, 463-468. doi: 10.1034/j.13993054.1991.830320.x

Costa, H., Gallego, S. M., and Tomaro, M. L. (2002). Effects of UV-B radiation on antioxidant defense system in sunflower cotyledons. Plant Sci. 162, 939-945. doi: 10.1016/S0168-9452(02)00051-1

Garg, N., and Manchanda, G. (2009). ROS gene ration in plants: boon or bane? Plant Biosyst. 143, 81-96. doi: 10.1080/11263500802633626

Giannakoula, A., Moustakas, M., Mylona, P., Ioannis, P., and Traianos, Y. (2008). Aluminium tolerance in maize is correlated with increased levels of mineral nutrients, carbohydrates and proline and decreased levels of lipid peroxidation and $\mathrm{Al}$ accumulation. J. Plant Physiol. 165, 385-396. doi: 10.1016/j.jplph.2007.01.014

Glick, B. R. (2007). Promotion of plant growth by bacterial ACC deaminase. Crit. Rev. Plant Sci. 26, 227-242. doi: 10.1080/07352680701572966 
Harman, G. E. (2011). Multifunctional fungal plant symbionts: new tools to enhance plant growth and productivity. New Phytol. 189, 647-649. doi: $10.1111 / j .1469-8137.2010 .03614 . x$

Harman, G. E., Howell, C. R., Viterbo, A., Chet, I., and Lorito, M. (2000). Trichoderma species-derived from research on Trichoderma afroharzianum T-22. Plant Dis. 84, 377-393. doi: 10.1094/PDIS.2000.84.4.377

Harman, G. E., Howell, C. R., Viterbo, A., Chet, I., and Lorito, M. (2004). Trichoderma species-opportunistic, avirulent plant symbionts. Nat. Rev. Microbiol. 2, 43-56. doi: 10.1038/nrmicro797

Hodges, D. M., DeLong, J. M., Forney, C. F., and Prange, R. K. (1999). Improving the thiobarbituric acid-reactive-substance assay for estimating lipid peroxidation in plant tissues containing anthocyanin and other interfering compounds. Planta 207, 604-611. doi: 10.1007/s0042500 50524

Khan, M. N., Siddiqui, M. H., Mohammad, F., Naeem, M., and Khan, M. M. A. (2010). Calcium chloride and gibberellic acid protect linseed (Linum usitatissimum L.) from $\mathrm{NaCl}$ stress by inducing antioxidative defence system and osmoprotectant accumulation. Acta Physiol. Plant 32, 121-132. doi: 10.1007/s11738-009-0387-z

Kochba, J., Lavee, S., and Roy Spiegel, P. (1977). Differences in peroxidase activity and isoenzymes in embryogenic and non-embryogenic 'Shamouti' orange ovular callus lines. Plant Cell Physiol. 18, 463-467.

Li, J. T., Qiu, Z. B., Zhang, X. W., and Wang, L. S. (2011). Exogenous hydrogen peroxide can enhance tolerance of wheat seedlings to salt stress. Acta Physiol. Plant 33, 835-842. doi: 10.1016/j.ecoenv.2014.03.014

Li, M. F., Sun, B. G., Xiao, Z. Z., and Sun, L. (2013). First characterization of a teleost Epstein-Barr virus-induced gene 3 (EBI3) reveals a regulatory effect of EBI3 on the innate immune response of peripheral blood leukocytes. Dev. Comp. Immunol. 41, 514-522. doi: 10.1016/j.dci.2013.07.022

Lichtenthaler, H. K. (1987). Chlorophylls and carotenoids: pigments of photosynthetic biomembranes. Methods Enzymol. 148, 350-382. doi: 10.1016/0076-6879(87)48036-1

Liu, S., Dong, Y., Xu, L., and Kong, J. (2014). Effects of foliar applications of nitric oxide and salicylic acid on salt-induced changes in photosynthesis and antioxidative metabolism of cotton seedlings. Plant Growth Regul. 73, 67-68. doi: 10.1007/s10725-013-9868-6

Livak, K. J., and Schmittgen, T. D. (2001). Analysis of relative gene expression data using real-time quantitative PCR and the $2^{-\Delta \Delta C_{\mathrm{T}}}$ method. Methods 25, 402-408. doi: 10.1006/meth.2001.1262

Lowry, O. H., Rosebrough, N. J., Farr, A. L., and Randall, R. J. (1951). Protein measurement with folin phenol reagent. J. Biol. Chem. 193, 265-275.

Lu, Z., Liu, D., and Liu, S. (2007). Two rice cytosolic ascorbate peroxidases differentially improve salt tolerance in transgenic Arabidopsis. Plant Cell Rep. 26, 1909-1917. doi: 10.1007/s00299-007-0395-7

Ma, L. J., Li, Y. Y., Yu, C. M., Wang, Y., Li, X. M., Li, N., et al. (2012). Alleviation of exogenous oligochitosan on wheat seedlings growth under salt stress. Protoplasma 249, 393-399. doi: 10.1007/s00709-0110290-5

Madhava Rao, K. V., and Sresty, T. V. S. (2000). Antioxidative parameters in the seedlings of pigeon pea (Cajanus cajan L. Millspaugh) in response to $\mathrm{Zn}$ and $\mathrm{Ni}$ stresses. Plant Sci. 157, 113-128.

Mahmood, M., Bidabadi, S. S., Ghobadi, C., and Gray, D. J. (2012). Effect of methyl jasmonate treatments on alleviation of polyethylene glycolmediated water stress in banana (Musa acuminata cv. 'Berangan', AAA) shoot tip cultures. Plant Growth Regul. 68, 161-169. doi: 10.1007/s10725-0129702-6

Mastouri, F., Björkman, T., and Harman, G. E. (2010). Seed treatment with Trichoderma harzianum alleviates biotic, abiotic, and physiological stresses in germinating seeds and seedlings. Phytopathology 100, 1213-1221. doi: 10.1094/PHYTO-03-10-0091

Miller, G., Suzuki, N., Ciftci-Yilmaz, S., and Mittler, R. (2010). Reactive oxygen species homeostasis and signalling during drought and salinity stresses. Plant Cell Environ. 33, 453-467. doi: 10.1111/j.1365-3040.2009.02041.x

Murakeozy, E. P., Nagy, Z., Duhaze, C., Bouchereau, A., and Tuba, Z. (2003). Seasonal changes in the levels of compatible osmolytes in three halophytic species of inland saline vegetation in Hungary. J. Plant Physiol. 160, 395-401. doi: 10.1078/0176-1617-00790
Naseby, D. C., Pascual, J. A., and Lynch, J. M. (2000). Effect of biocontrol strains of Trichoderma on plant growth, Pythium ultimum polulations, soil microbial communities and soil enzyme activities. J. Appl. Microbiol. 88, 161-169. doi: 10.1046/j.1365.2612.2000.00939.x

Özdemir, F., Bor, M., Demiral, T., and Türkan, I. (2004). Effects of 24-epibrassinolide on seed germination, seedling growth, lipid peroxidation, proline content and antioxidative system of rice (Oryza sativa L.) under salinity stress. Plant Growth Regul. 42, 203-211. doi: 10.1023/B:GROW.0000026509.25995.13

Papavizas, G. C., and Lumsden, R. D. (1982). Improved medium for isolation of Trichoderma spp. from soil. Plant Dis. 66, 1019-1020. doi: 10.1094/PD66-1019

Parida, A. K., Das, A. B., and Mohanty, P. (2004). Defense potentials to $\mathrm{NaCl}$ in a mangrove, Bruguiera parviflora: differential changes of isoforms of some antioxidative enzymes. J. Plant Physiol. 161, 531-542. doi: 10.1018/0176-161701084

Phang, T. H., Shao, G. H., and Lam, H. M. (2008). Salt tolerance in soybean. J. Integr. Plant Biol. 50, 1196-1212. doi: 10.1111/j.1744-7909.2008. 00760.x

Qi, W. Z., Liu, H., Liu, P., Dong, S. T., Zhao, B. Q., So, H. B., et al. (2012). Morphological and physiological characteristics of corn (Zea mays L.) roots from cultivars with different yield potentials. Eur. J. Agron. 38, 54-63. doi: 10.1016/j.eja.2011.12.003

Qi, W. Z., and Zhao, L. (2013). Study of the siderophore-producing Trichoderma asperellum Q1 on cucumber growth promotion under salt stress. J. Basic Microbiol. 53, 355-364. doi: 10.1002/jobm.201200031

Qiu, Z. B., Guo, J. L., Zhu, A. J., Zhang, L., and Zhang, M. M. (2014). Exogenous jasmonic acid can enhance tolerance of wheat seedlings to salt stress. Ecotoxicol. Environ. Saf. 104, 202-208. doi: 10.1016/j.ecoenv.2014.03.014

Qiu, Z. B., Li, J. T., Zhang, M. M., Bi, Z. Z., and Li, Z. L. (2013). He-Ne laser pretreatment protects wheat seedlings against cadmium-induced oxidative stress. Ecotoxicol. Environ. Saf. 88, 135-141. doi: 10.1016/j.ecoenv.2012. 11.001

Rawat, L., Singh, Y., Shukla, N., and Kumar, J. (2011). Alleviation of the adverse effects of salinity stress in wheat (Triticum aestivum $\mathrm{L}$.) by seed biopriming with salinity tolerant isolates of Trichoderma harzianum. Plant Soil 347, 387-400. doi: 10.1007/s11104-011-0858-z

Rivero, R. M., Mestre, T. C., Mittler, R., Rubio, F., Sanchez, F. G., and Martinez, V. (2014). The combined effect of salinity and heat reveals a specific physiological, bio-chemical and molecular response in tomato plants. Plant Cell Environ. 37, 1059-1073. doi: 10.1111/pce.12199

Rubio, M. B., Quijada, N. M., Pérez, E., Domínguez, S., Monte, E., and Hermosa, R. (2014). Identifying beneficial qualities of Trichoderma parareesei for plants. Appl. Environ. Microbiol. 80, 1864-1873. doi: 10.1128/AEM.03375-13

Sahi, C., Singh, A., Kumar, K., Blumwald, E., and Grover, A. (2006). Salt stress response in rice: genetics, molecular biology, and comparative genomics. Funct. Integr. Genomics 6, 263-284. doi: 10.1007/s10142-006-0032-5

Sairam, R. K., and Tyagi, A. (2004). Physiology and molecular biology of salinity stress tolerance in plants. Curr. Sci. 86, 407-421. doi: 10.1007/1-40204225-6

Seckin, B., Sekmen, A. H., and Türkan, I. (2008). An enhancing effect of exogenous mannitol on the antioxidant enzyme activities in roots of wheat under salt stress. J. Plant Growth Regul. 28, 12-20. doi: 10.1007/s00344-008-9068-1

Shekhawat, G. S., Verma, K., Jana, S., Singh, K., Teotia, P., and Prasad, A. (2010). In vitro biochemical evaluation of cadmium tolerance mechanism in callus and seedlings of Brassica juncea. Protoplasma 239, 31-38. doi: 10.1007/s00709-0090079-y

Shoresh, M., Mastouri, F., and Harman, G. H. (2010). Induced systemic resistance and plant responses to fungal biocontrol agents. Annu. Rev. Phytopathol. 48, 21-43. doi: 10.1146/annurev-phyto-073009-114450

Simaei, M., Khavarinejada, R. A., Saadatmanda, S., Bernardb, F., and Fahimia, H. (2011). Interactive effects of salicylic acid and nitric oxide on soybean plants under $\mathrm{NaCl}$ salinity. Russ. J. Plant Physiol. 58, 783-790. doi: $10.1134 / \mathrm{S} 1021443711050220$

Singh, P. K., and Gautam, S. (2013). Role of salicylic acid on physiological and biochemical mechanism of salinity stress tolerance in plants. Acta Physiol. Plant 35, 2345-2353. doi: 10.1007/s11738-013-1279-9 
Tariq, A., Masroor, M., Khan, A., Jaime, A., da Teixeira, S., Mohd, I., et al. (2011). Role of salicylic acid in promoting salt stress tolerance and enhanced artemisinin production in Artemisia annua L. J. Plant Growth Regul. 30, 425-435. doi: 10.1007/s00344-011-9205-0

Tian, X. Y., He, M. R., Wang, Z. L., Zhang, J. W., Song, Y. L., He, Z. L., et al. (2015). Application of nitric oxide and calcium nitrate enhances tolerance of wheat seedlings to salt stress. Plant Growth Regul. 77, 343-356. doi: 10.1007/s10725015-0069-3

Trotel, P., Bouchereau, A., Niogret, M. F., and Larher, F. (1996). The fate of osmo-accumulated proline in leaf discs of Rape (Brassica napus L.) incubated in a medium of low osmolarity. Plant Sci. 118, 31-45. doi: 10.1016/01689452(96)04422-6

Woodward, A. J., and Bennett, I. J. (2005). The effect of salt stress and abscisic acid on proline production, chlorophyll content and growth of in vitro propagated shoots of Eucalyptus camaldulensis. Plant Cell Tissue Organ Cult. 82, 189-200. doi: 10.1007/s11240-005-0515-4

Yedidia, I., Shoresh, M., Kerem, Z., Benhamou, N., Kapulnik, Y., and Chet, I. (2003). Concomitant induction of systemic resistance to Pseudomonas syringae pv. lachrymans in cucumber by Trichoderma asperellum (T-203) and accumulation of phytoalexins. Appl. Environ. Microbiol. 69, 7343-7353. doi: 10.1128/AEM.69.12.7343-7353.2003

Younis, M. E., Hasaneen, M. N. A., and Kazamel, A. M. S. (2010). Exogenously applied ascorbic acid ameliorates detrimental effects of $\mathrm{NaCl}$ and mannitol stress in Vicia faba seedlings. Protoplasma 239, 39-48. doi: 10.1007/s00709-0090080-5
Zhang, S. W., Gan, Y. T., and Xu, B. L. (2014a). Efficacy of Trichoderma longibrachiatum in the control of Heterodera avenae. BioControl 59, 319-331. doi: 10.1007/s10526-014-9566-y

Zhang, S. W., Gan, Y. T., Xue, Y. Y., and Xu, B. L. (2014b). The parasitic and lethal effects of Trichoderma longibrachiatum against Heterodera avenae. Biol. Control 72, 1-8. doi: 10.1016/j.biocontrol.2014.01.009

Zhang, S. W., Gan, Y. T., and Xu, B. L. (2015). Biocontrol potential of a native species of Trichoderma longibrachiatum against Meloidogyne incognita. Appl. Soil Ecol. 94, 21-29. doi: 10.1016/j.apsoil.2015.04.010

Zou, P., Li, K. C., Liu, S., Xing, R. G., Qin, Y. K., Yu, H. H., et al. (2015). Effect of chitooligosaccharides with different degrees of acetylation on wheat seedlings under salt stress. Carbohydr. Polym. 126, 62-69. doi: 10.1016/j.carbpol.2015.03.028

Conflict of Interest Statement: The authors declare that the research was conducted in the absence of any commercial or financial relationships that could be construed as a potential conflict of interest.

Copyright (C) 2016 Zhang, Gan and Xu. This is an open-access article distributed under the terms of the Creative Commons Attribution License (CC BY). The use, distribution or reproduction in other forums is permitted, provided the original author(s) or licensor are credited and that the original publication in this journal is cited, in accordance with accepted academic practice. No use, distribution or reproduction is permitted which does not comply with these terms. 